\title{
NANOTECHNOLOGY - NEW TRENDS IN THE TREATMENT OF BRAIN TUMOURS
}

\author{
Petr Krůpa ${ }^{1}$, Svatopluk Řehák', Daniel Diaz-Garcia ${ }^{2}$,Stanislav Filip ${ }^{3}$
}

Charles University in Prague, Faculty of Medicine in Hradec Králové, and University Hospital Hradec Králové, Czech Republic: Department of Neurosurgery ${ }^{1}$, Department of Histology and Embryology², Department of Oncology and Radio-therapy ${ }^{3}$

Summary: High grade gliomas are some of the deadliest human tumours. Conventional treatments such as surgery, radiotherapy and chemotherapy have only a limited effect. Nowadays, resection is the common treatment of choice and although new approaches, such as perioperative magnetic resonance imaging or fluorescent microscopy have been developed, the survival rate of diagnosed patients is still very low. The inefficacy of conventional methods has led to the development of new strategies and the significant progress of nanotechnology in recent years. These platforms can be used either as novel imaging tools or to improve anticancer drug delivery into tumours while minimizing its distribution and toxicity in healthy tissues. Amongst the new nanotechnology platforms used for delivery into the brain tissue are: polymeric nanoparticles, liposomes, dendrimers, nanoshells, carbon nanotubes, superparamagnetic nanoparticles and nucleic acid based nanoparticles (DNA, RNA interference [RNAi] and antisense oligonucleotides [ASO]). These nanoparticles have been applied in the delivery of small molecular weight drugs as well as macromolecules - proteins, peptides and genes. The unique properties of these nanoparticles, such as surface charge, particle size, composition and ability to modify their surface with tissue recognition ligands and antibodies, improve their biodistribution and pharmacokinetics. All of the above mentioned characteristics make of nanoplatforms a very suitable tool for its use in targeted, personalized medicine, where they could possibly carry large doses of therapeutic agents specifically into malignant cells while avoiding healthy cells. This review poses new possibilities in the large field of nanotechnology with special interest in the treatment of high grade brain tumours.

Key words: Biotechnology; Nanotechnology; Target therapy; Brain tumour

\section{Introduction}

There is a great interest in the development of new biotechnological and nanobiotechnological methods that can be used as either diagnostic or therapeutic tools. Improving the efficiency of anticancer treatments is the goal of this research as it is also to minimize the distribution and toxic effects of these drugs in healthy tissues. There is a relatively recent boom in the innovation of nanobiological and nanotechnological platforms such as: polymeric nanoparticles, liposomes, dendrimers, nanoshells, carbon nanomaterials, superparamagnetic nanoparticles conjugated with DNA, RNA interference (RNAi), and antisense oligonucleotides (ASO). These nanotechnological platforms have diverse physical and chemical properties that confer them with new biological distribution, availability and efficiency in anticancer treatment (1).

\section{Nanoparticles and the blood-brain barrier}

The blood-brain barrier regulates the interface between blood, brain, and cerebrospinal fluid (liquor), allowing some substances to migrate in a single or bi-directional manner; in some instances, however, this barrier appears to be al- most impermeable to others. The blood-brain barrier ensures an optimal environment for brain functionality, protects it against harmful substances, and allows the supply of nutrients necessary for its metabolism (1).

The blood-brain barrier can be divided into three major components:

1.1 Hemato-encephalic barrier makes the boundary-line between the brain capillaries and brain tissue. Movement of the substances is dependent on whether they are fat-soluble or on the transport system.

1.2 Hemato-liquor barrier separates blood and the cerebrospinal fluid. It is mostly made of the choroid plexuses' epithelium, which produces liquor. Epithelial cells are bound with tight junctions, which are more permeable than those in the brain capillaries. The surface in contact with the liquor contains microvilli, which significantly increases epithelial surface. Another component of the hemato-liquor barrier are the pia mater's capillaries, which are fenestrated and are similar to capillaries in any other region of the body. The hemato-liquor barrier is more permeable and enables the transport of proteins from plasma to liquor by pinocytosis or by specific transport systems. Any disorder in this barrier will be followed by higher concentrations of proteins in the liquor. 
1.3 Encephalo-liquor barrier is a layer of glial fibres on the surface of the brain and also ependyma of the ventricles. This barrier is more permeable than the hemato-liquor barrier. Transport of substances happens through spaces between cells in the glia and the intercellular spaces of the ependyma. Substances, similar in size to proteins, can diffuse in both directions through this barrier.

The blood-brain barrier (BBB) enables the transport of a limited number of small hydrophilic molecules (MW $<400 \mathrm{Da}$ ). Many anticancer drugs are large hydrophilic molecules, which makes them unable to cross the BBB. A potential possibility regarding the crossing of the $\mathrm{BBB}$ is the conjugation of these big molecules with a small nanocarriers, which could help distribute the drug into the brain $(2,3,4)$.

There are several transport routes by which drugs, combined with a nanocarrier, could move across the BBB, such as passive diffusion (paracellular aqueous diffusion and transcellular lipophilic diffusion), and receptor-mediated endocytosis (receptor-mediated transcytosis, carrier-mediated transport and adsorptive mediated transcytosis). Passive diffusion can be facilitated by increasing the concentration of a drug in the plasma, resulting in a larger osmotic gradient at the BBB and thus increasing the amount of drug molecules entering the CNS. Receptor-mediated endocytosis is a common strategy for nanoparticle (NP) brain targeting, which relies on the interaction of the NP surface ligand with a specific receptor in the BBB. Receptor-mediated transcytosis consists of several cascading processes involving the interaction of engineered nanoparticles (NPs) with the targeted receptor, creation of endocytotic vesicles, transcytosis across the BBB endothelial cells, and subsequent exocytosis of NPs. Exocytosis depends on the affinity strength between the cell receptor and the ligand on the surface of the nanoparticles, thus there is a higher amount of nanoparticles in endothelial cells than in the brain parenchyma $(5,6)$.

In the delivery of anticancer drugs into tumours, the phenomenon called "enhanced permeability a retention" (EPR), first described by Matsumura and Maeda in 1986, is a very important factor (7). Most solid tumours have blood vessels with defective architecture and usually produce extensive amounts of diverse vascular permeability factors, therefore exhibiting an enhanced vascular permeability. Due to EPR, macromolecules larger than $40 \mathrm{kDa}$ selectively leak out from tumour vessels and accumulate in the tumour tissue. In contrast, this EPR effect-driven drug delivery does not occur in normal tissues.

\section{Nanoparticles' refinement of imaging, detection and biomarkers of brain tumours}

Nanoparticles are promising "theranostic" agents in the treatment of brain tumours. They can be used either as a diagnostic tool, mainly in imaging methods, as well as therapeutically. In clinical practice, there could be less invasive procedures for the patient and could also shorten of the delay between the diagnostic and therapeutic process. The use of nanoparticles to label cancer cells has become a new trend in the diagnostic phase of brain tumours, making them easier to detect earlier by standard imaging methods (1). The leading imaging methods for brain tumours include computed tomography (CT), and magnetic resonance imaging (MRI). Magnetic resonance commonly employs enhancing agents such as magnetic nanoparticles with advantageous properties such as increased contrast sensitivity, binding avidity, and targeting specificity. Also promising, is the contrasting agent gadolinium conjugated with chitosan and other nanoparticles (8). These agents can be injected directly into the tumour (stereotactic delivery), or can be applied intravenously and then migrate to the cancerous focus. Classic contrast agents do not usually cross the BBB because of their high molecular weight so the conjugation with nanoparticles able to cross the barrier seems to be a very elegant solution of this problem. These conjugates can additionally be labelled with specific membrane antibodies, i.e. $\alpha$-EGFR (9).

\section{Nanotechnology-based drug delivery into brain tumours}

Surgery currently remains as the basic treatment for brain tumours, consisting in the physical removal of the tumour, and the peripheral infiltrating part is often targeted by supplementary treatments. In some cases, surgery becomes unadvisable due to the less than favourable placement of the tumour, e.g. near major blood vessels, or in the brain stem. If surgery becomes impossible, the only viable alternative for the patient are chemotherapy and radiotherapy treatments. Chemotherapy has, on the other hand, a high systemic effect on healthy cells and tissues. In the search for targeted chemotherapy, several nanoparticles have become the main subject of research in this field. Nanoparticles can act as a "postman" in the specific delivery of a chemotherapeutic drug to cancer cells, which will then be eliminated after exposition to this drug. The treatment drugs are usually encapsulated within the nanoparticle, which can be shaped as a cage, shell, bubble etc. However, drug delivery into the tumour cells could also be non-specific. Non-specific delivery is based on the principle that tumours contain leaky capillaries, allowing thus the accumulation of drug loaded nanoparticles within the cancerous tissue (10).

\section{Polymeric nanoparticles}

Polymeric nanoparticles belong to the most powerful nanotechnologic platforms and have been shown as versatile carriers for the targeted distribution of therapeutic cancer drugs (11). Polymeric nanoparticles are able to carry not only small drug molecules but also macromolecules like genes and proteins (12).

The nanostructure of these particles provides them with good penetrance across cell membranes, stability in the blood stream, and very low toxicity; most importantly, they 
are easily manufactured. In addition, their surface can be modified into various forms to make them suitable for different medical uses. For their distribution in the central nervous system, they are commonly synthesized using polysaccharides, proteins, amino acids, polyesters, polyethylamins, etc.

Recently, specific nanoparticles have been developed that can be degraded in the body via natural metabolic pathways within the organism. This group of nanoparticles includes Polylactides (PLA), Polyglycolides (PGA), Poly(D,Llactic-co-glycolides) acid (PLGA), Polyanhydrides, Polyorthoesters, Polycyanoacrylates, Polyalkylcyanoacrylate, Polycaprolactone etc. $(13,14)$. Nowadays, there is very broad range of materials and choosing the type depends mainly on the final usage.

Polymeric nanoparticles permeate to the brain by various mechanisms. Firstly, it can be by transcytosis through endothelial cells; secondly, by opening of the tight junctions of the brain capillaries; and lastly, by adhering to the walls of the capillaries, resulting in a higher osmotic gradient of concentration through the $\mathrm{BBB}$ (15). On the other hand, there are some major disadvantages to polymeric nanoparticles, as after intravenous application they are swiftly selected by the reticuloendothelial system (RES) and distributed to the liver, spleen and bone marrow, where they are eliminated from the organism. The half-life of the particles in the bloodstream is usually around $2-3$ minutes $(16,17)$. The speed and level of elimination depends mainly on the size of the carriers, their surface charge and properties. On behalf of a longer circulation half-life, several surface modifications have been implemented, such as coating and linking with polyethylenglycol (PEG), use of surfactants as coating for the NPs, and conjugation of NPs with a specific ligand such as antibodies, peptides or proteins. Currently, several drugs carried by polymeric nanoparticles are in clinical trials, like doxorubicin (SP1049C), paclitaxel (NK105), SN-38 (NK012) and cisplatin (NC-6004).

\section{Liposomes}

Liposomes are self-assembled, self-contained colloidal nanocarriers that possess phospholipid bilayer membranes. Phospholipids are heterogeneous molecules containing phosphoric residues, polar head groups, and non-polar alkyl chains (18), that form part of the cell membrane, play an important role in signal transduction mechanisms, and are arranged according to fluid mosaic pattern in biological membranes.

Many liposome formulations with various anticancer agents have been shown biocompatible and with less toxic effects than the drug itself, thus liposomes are ideal non-toxic biodegradable carriers. Liposomes are passively targeted to different tumours because they can circulate in the blood compartment for longer periods of time and perfuse better into cancerous tissues. The phospholipid bilayer of the liposome protects the drug from degradation in the body while being targeted to the tumour site; it also prevents the exposure of healthy tissues to the active drug while in blood circulation. The distribution of liposomes into the tumour interstitium is mainly via extravasation through the discontinuous endothelium of the tumour microvasculature.

There are two distinct types of liposomal carriers, targeted and non-targeted. Non-targeted liposomes do not enter to the tumour cells, so they stay only in the tumour interstitium. The specific targeting of drugs employ carriers such as serum proteins, immunoglobulins, synthetic polymers, liposomes, niosomes, microspheres, erythrocytes, reverse micelles, pharmacosomes, and monoclonal antibodies. An example of antibody-conjugated liposomes is OX26, which binds to the transferrin receptor (19). Targeted liposomal drugs are more powerful, because they result in the breakdown of the liposomes by lysosomes and an increased delivery of the drug to the nucleus, resulting in greater cytotoxic effects in the tumour area (20).

Liposomal carriers can be used in several chemotherapeutics, such as doxorubicin, dunosome, vincristine etc. Concerning brain tumours, it has been pointed out in a number of studies that doxorubicin has great potential when used clinically against both primary and metastatic brain tumours and that there is an improved survival rate of glioma patients treated by direct intratumoral infusion of doxorubicin, furthermore, doxorubicin is useful against multiple tumour types $(21,22)$.

Glioblastoma multiforme is highly vascularized with a leaky vasculature, and thus may be amenable to liposome-based drug delivery systems that lead to enhanced drug deposition while limiting systemic drug exposure (23). Receptor-targeted liposomal doxorubicin has been found to be effective in targeting glioma tumours in a brain tumour model (24). It has been reported that human brain tumour cell lines express high levels of plasma membrane interleukin-4 receptors, so targeting liposomal carriers with interleukin-4 antibodies may be a useful approach for tumour treatment (25).

\section{Dendrimers}

Dendrimers are polymeric molecules, chemically synthesized with well-defined shape, size and nanoscopic physicochemical properties reminiscent of proteins (26). From a chemical point of view, dendrimers can be manufactured from peptides, lipids, polysaccharides, and other synthetic materials (27).

Dendrimers are considered a promising new enhancement in current drug delivery methods, imaging methods, and photodynamic therapy. Dendrimers whch are used for drug delivery are designed to improve the pharmacokinetics and biodistribution of drugs, and to provide a controlled drug release aimed at the targeted tissues (28). Dendrimers interact with drug molecules physically by electrostatic interactions, covalent binding, or by encapsulation of the drug into the dendrimer pores (29). Regarding cancer treatment, the conjugation of these dendrimers with doxorubicin, 5-fluoruracil, or cisplatine, could be promising. 


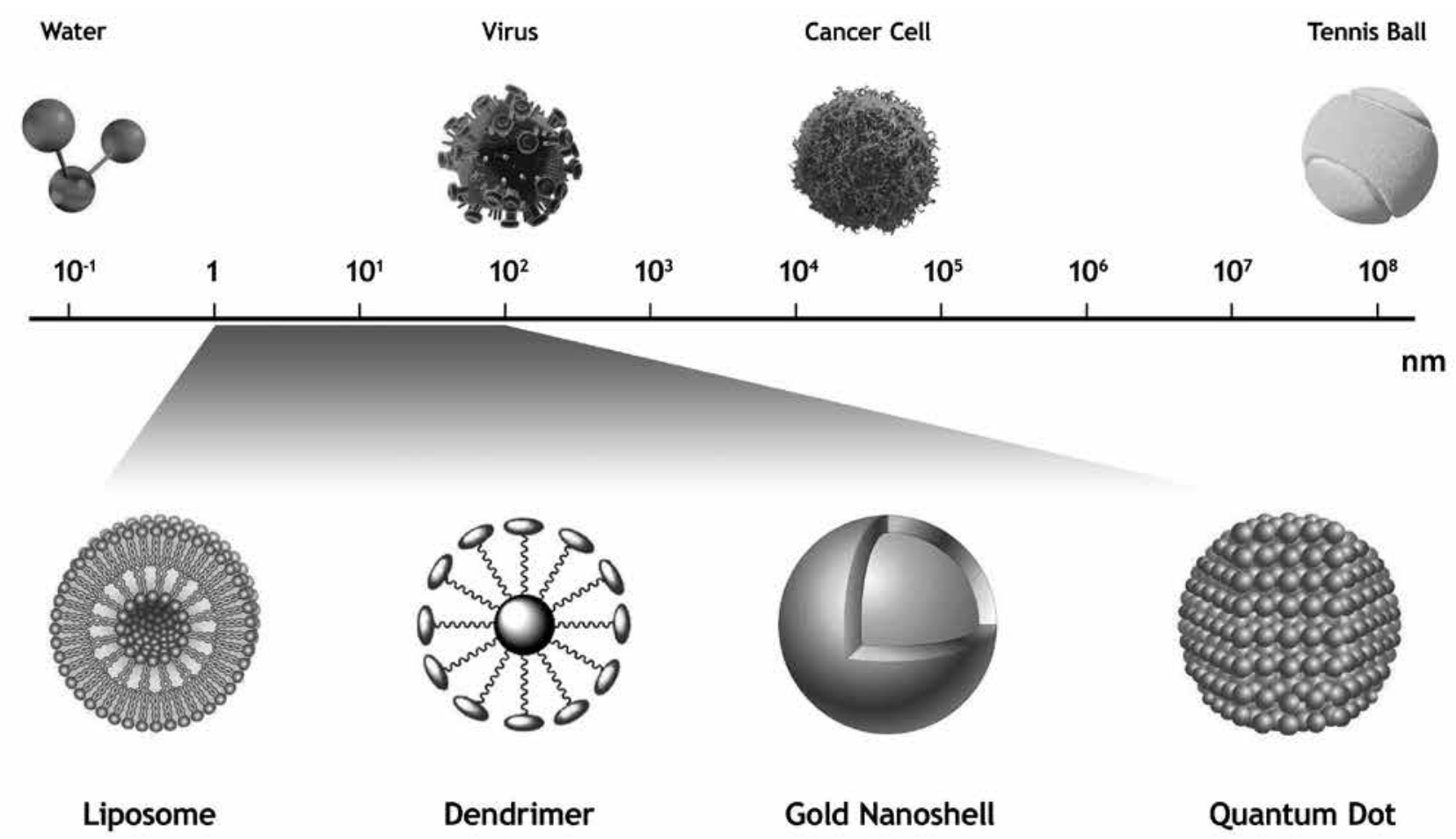

Fig. 1: Schemes of mentioned nanoparticles with comparison to some other structures on the nano-sized scale.

Photodynamic therapy relies on the activation of a photosensitizing agent with visible or near-infrared light. Upon excitation, a highly energetic state is formed which, upon reaction with oxygen, releases a highly reactive oxygen singlet capable of inducing necrosis and apoptosis in tumour cells (30). In recent years, the improved delivery of 5-aminolaevulinic acid using dendrimer technology has been the subject of continuous research. This acid is used in the imaging of glioblastoma to demarcate tumour boundaries for surgery. Specific targeting of this acid by the dendrimers could increase the precision of this method.

Fine imaging of brain tumours involves the use of MRI, which is also the standard operating procedure in the planning of surgery. Gadolinium (Gd) paramagnetic contrast agents have been fused with dendrimer molecules into imaging complexes for MRI over the last two decades for contrast enhancement, improved clearance characteristics, and potential targeting (31).

\section{Gold Nanoshells}

Nanoshells are additional novel structures within the big group of nanoparticles. Most nanoshells are developed from a gold core, but recently, some types are made of silver as well. Gold nanoshells are nanoparticles composed of an organic (polymer or lipid) or inorganic (metal) core coated with a thin layer of gold. The most intensively researched options in the use of gold nanoshells for the treatment of malignant brain tumours are thermoablation (32) and drug delivery, which often contains doxorubicin (33).

In general, gold nanoshells that are intravenously administered as they are passively accumulate in tumours, the hallmarks of which are leaky vasculature and minimal lymphatic drainage, because of their enhanced permeability and retention. On the other hand, gold nanoshells have the major disadvantage in a short half-life within circulation. To solve this problem, they are usually associated with polyethylene glycol to enhance their biodistribution and to evade the mononuclear phagocytic system. The light-induced release of doxorubicin with near-infrared light has also been a subject of study (33), as drug concentration in the treated tissue was significantly higher after exposition to the near-infrared light as compared with non-treated controls, thus near-infrared light can be used as a trigger for drug release in the needed specific location.

\section{Superparamagnetic nanoparticles}

Magnetic nanoparticles, composed of $\mathrm{Fe}_{2} \mathrm{O}_{3}$ or $\mathrm{Fe}_{3} \mathrm{O}_{4}$, are promising agents with both diagnostic and therapeutic properties as they are capable of showing the location of a lesion and treatment delivery thanks to their unique magnetic properties. Their major advantage is, they are no longer magnetized after removal of the magnetic field. In general, superparamagnetic particles are classified in two types according to their size: SPIONs (superparamagnet- 
ic iron oxide nanoparticles) of approximately $100 \mathrm{~nm}$ size, and USPIONs (ultrasmall superparamagnetic iron oxide nanoparticles) which are smaller than $50 \mathrm{~nm}$. They both have unique properties based on a superparamagnetic phenomenon characterized by a large magnetic moment in the presence of a static external magnetic field, making them excellent contrast agents for magnetic resonance imaging (34, 35 ). In the last decade, USPIONs have become increasingly common since they can be visualized in T1-weighted MRI sequences as a hyperintense signal (bright) or in T2-weighted MRI sequences as a hypointense signal (dark) $(36,37$, 38). USPIONs are also more suitable than Gd agents because of its ability to provide contrast for longer periods of time (39). They are also more gentle to patients with some form of kidney disease as preliminary studies have shown no adverse renal effects $(40,41)$.

USPIONs are taken up by malignant tumour cells as well as by phagocytic microglia, although this uptake is not as selective as desired. Searching for an improved and specific uptake by tumour cells, several methods have been developed. MNPs can be conjugated with a purified antibody that selectively binds to the epidermal growth factor receptor deletion mutant EGFRvIII. This deletion is expressed by a cell population of glioblastoma multiforme tumours (GBM) (42). Another example is the conjugation of MNPs with chlorotoxin, which specifically binds to over-expressed matrix metalloproteinase-2 (MMP-2), found on the surface of GBM cells $(43,44)$.

From a therapeutic point of view, the most promising method in the treatment of GBM using SPIONs is thermotherapy. MNPs are exposed to an alternating magnetic field, generating focal heat by Brownian and Néel relaxations. Temperature variations range between $41{ }^{\circ} \mathrm{C}$ and $46^{\circ} \mathrm{C}$ causing cells to undergo heat stress promoting protein denaturation, miss-folding, and aggregation, resulting in apoptosis and heat shock protein expression. MNPs designed for thermotherapy can be made of different metals including: manganese, iron, cobalt, nickel, magnesium, zinc, and their respective oxide forms $(45,46)$.

Recently, Maier-Hauff et al. showed a significant increase in GBM patient survival rates with no, or minor, side effects of the treatment (47), in which magnetic nanoparticles were stereotactically delivered into the tumour and then heated by an external, alternating $(100 \mathrm{kHz})$ magnetic field up to $82{ }^{\circ} \mathrm{C}$. Between 2014 and 2015 , a vast clinical trial by the MagForce Company in Germany has been scheduled.

\section{Carbon nanotubes}

Carbon nanotubes are well structured, hollow, cylindrical graphene nanomaterials with a wide range of properties, including high aspect ratio, high surface area, and ultralight weight (45). A carbon nanotube comprising a singular graphene tube is called a "single wall carbon nanotube" (SWCNT), and concentric graphene tubes nested within each other are called "multi-wall carbon nanotubes", (MWCNT).
In comparison with other nanomaterials, carbon nanotubes appear to be more dynamic in their biological application as they have the potential to be used not only in imaging, but also for drug delivery and thermal ablation $(48,49)$.

Chemotherapeutic agents have some limitations and disadvantages due to their toxic side effects and lack of penetration to all compartments (e.g. through blood-brain-barrier). Carbon nanotubes are promising vehicles for targeted drug delivery (50) as these can be either attached to the outer surface of the nanotubes via functional groups or be loaded inside the nanotube. For the direct targeting to the tumour cells, the nanotube can be labelled with various antibodies.

Another alternative in the treatment of cancer using these nanotubes is thermoablation. The temperature of the carbon nanotubes can be increased to over $60{ }^{\circ} \mathrm{C}$ within 2 minutes when exposed to near infrared wavelengths of 700-1100 $\mathrm{nm}$ (51). In addition to carbon nanotubes, the previously mentioned magnetic nanoparticles can also be used in thermal treatment strategies, although they are activated by an alternating magnetic field instead of near infrared light. Disadvantage of these magnetic nanoparticles is their toxicity to non-target cells; however, this problem can be overcome by inserting them into carbon nanotubes. Carbon nanotubes can act as a shell, protecting the biological environment against oxidation and toxicity of the magnetic nanoparticles. The benefit of using carbon nanotubes is that they do not affect the properties of these magnetic nanoparticles and are less toxic.

New variations of carbon nanotubes are currently in research as non-viral vectors for gene therapy, for which they seem to be optimal since they can cross the cell membrane by endocytosis, and also because DNA can be transferred without being degraded (52).

Carbon nanotubes are very promising materials in the treatment and diagnosis of cancer. Despite their advantages, the problem regarding their toxicity to healthy tissue, causing oxidative stress, still remains. The toxicity of carbon nanotubes is reviewed in detail in Li-Chu Ong et al.'s work (53). It has been reported recently that treating the carbon nanotubes with polyethylene glycol (PEG) makes a more effective, and less toxic, drug delivery vehicle than untreated nanotubes, but further research complemented with in vitro and in vivo testing is highly advisable (54).

\section{Nucleid acid-based nanoparticles (DNA, RNAi, and ASO)}

Antisense oligonucleotides are synthetic, single DNA strands that anneal with target mRNA sequences. Because of their specific hybridization they can be used to modulate the expression of genes involved in tumorigenesis (55) by inhibiting the correct translation and promoting the degradation of the targeted mRNA, altering the subsequent cascades regulating cellular proliferation, differentiation, apoptosis, and tumour homeostasis. 
Tab. 1: Nanomaterials for treatment of GBM.

\begin{tabular}{|c|c|c|c|c|}
\hline Nanomaterial & Description & Field & Size & References \\
\hline DEG-US-Gd2O3 & $\begin{array}{l}\text { Ultra-small gadolinium oxide nanoparticles } \\
\text { (US-Gd2O3) covered with diethylene glycol } \\
\text { (DEG) labeling glioblastoma cells GL-261. }\end{array}$ & MRI imaging & $1-2 \mathrm{~nm}$ & 67 \\
\hline ANG-NP-paclitaxel & $\begin{array}{l}\text { Angiopep-conjugated PEG-PCL nanoparticles } \\
\text { loaded with paclitaxel for targeting the tumor via } \\
\text { lipoprotein receptor-related resulting in apoptosis } \\
\text { of U87 MG glioma cells. }\end{array}$ & Liposomal treatment & $<100 \mathrm{~nm}$ & 68 \\
\hline $\begin{array}{l}\text { Pegylated liposomal } \\
\text { doxorubicin (PLD) }\end{array}$ & $\begin{array}{l}\text { The liposomal encapsulation of doxorubicin } \\
\text { using polyethylene glycol (PEG) liposomes } \\
\text { leading to increased efficacy of the distribution } \\
\text { and accumulation into tumors. }\end{array}$ & Liposomal treatment & $<100 \mathrm{~nm}$ & 69 \\
\hline $\begin{array}{l}\text { Methotrexate (MTX)- } \\
\text { loaded dendrimers }\end{array}$ & $\begin{array}{l}\text { The efficacy of methotrexate- (MTX-)loaded } \\
\text { dendrimers was established against U87 MG and } \\
\text { U343 MGa cells. The amount of MTX transport- } \\
\text { ed across BBB was three to five times more after } \\
\text { loading in the dendrimers. }\end{array}$ & Dendrimer treatment & $11 \mathrm{~nm}$ & 70 \\
\hline $\begin{array}{l}\text { Nanoshells consisting } \\
\text { of silica cores and thin gold } \\
\text { shell }\end{array}$ & $\begin{array}{l}\text { Intravenous injections of PEG-coated nano- } \\
\text { shells followed by transdermal irradiation of } \\
800 \mathrm{~nm} \text { diode laser. There was significant longer } \\
\text { tumour-free period. }\end{array}$ & $\begin{array}{l}\text { Gold nanoshell } \\
\text { phototherapy }\end{array}$ & $150 \mathrm{~nm}$ & 71 \\
\hline $\begin{array}{l}\text { HB1.F3-CD } \\
\text { human NSC loaded with } \\
\text { oncolytic virus CRAd-S-pk7 }\end{array}$ & $\begin{array}{l}\text { The HB1.F3-CD human NSC line is a cell carrier } \\
\text { for the delivery of a glioma tropic oncolytic virus } \\
\text { CRAd-Survivin-pk7 (CRAd-S-pk7). }\end{array}$ & $\begin{array}{l}\text { Stem Cell-Based } \\
\text { Gene Therapy }\end{array}$ & $10 \mu \mathrm{m}$ & 72 \\
\hline Oncolytic HSV-1, G207 & $\begin{array}{l}\text { Oncolytic HSV-1 virus used in recurrent glioma } \\
\text { patients received by stereotactic intratumoral } \\
\text { inoculations followed by single focal irradiation. }\end{array}$ & $\begin{array}{l}\text { Virus-based Gene } \\
\text { Therapy }\end{array}$ & $125 \mathrm{~nm}$ & 73 \\
\hline $\begin{array}{l}\text { NanoTherm }{ }^{\circledR}-\text { iron-oxide } \\
\text { magnetite (Fe3O4) with } \\
\text { an aminosilane coating }\end{array}$ & $\begin{array}{l}\text { Intratumoral instillation of an aqueous disper- } \\
\text { sion of iron-oxide (magnetite) nanoparticles is } \\
\text { followed by subsequent heating of the particles in } \\
\text { an alternating magnetic field with strength of the } \\
\text { alternating }(100 \mathrm{kHz}) \text { magnetic field. }\end{array}$ & $\begin{array}{l}\text { Superparamagnetic } \\
\text { nanoparticles, } \\
\text { thermotherapy }\end{array}$ & $12 \mathrm{~nm}$ & 74 \\
\hline Carbon nanotubes & $\begin{array}{l}\text { Therapeutic potential of hyperthermia-induced } \\
\text { thermal ablation using the sequential administra- } \\
\text { tion of carbon nanotubes (CNT) and near-infrared } \\
\text { radiation (NIR) on glioma tumor cell lines (U251, } \\
\text { U87, LN229, T98G). }\end{array}$ & $\begin{array}{l}\text { Carbon nanotubes, } \\
\text { thermotherapy }\end{array}$ & $104 \mathrm{~nm}$ & 75 \\
\hline $\begin{array}{l}\text { Bcl2L12-targeting } \\
\text { SNAs (siL12-SNAs) }\end{array}$ & $\begin{array}{l}\text { SNAs targeting the oncoprotein Bcl2Like12 } \\
\text { (Bc12L12) - an effector caspase and p53 inhib- } \\
\text { itor overexpressed in GBM were effective in } \\
\text { knocking down endogenous Bcl2L12 mRNA and } \\
\text { enhancing p53 activity. }\end{array}$ & $\begin{array}{l}\text { Nucleid acid-based } \\
\text { nanoparticles }\end{array}$ & $\sim 10 \mathrm{~nm}$ & 76 \\
\hline
\end{tabular}

The most currently advanced AS technology consists of a phosphorothioate-modifiedAS-ODN(Trabedersen,AP12009, Antisense pharma) directed against the transforming growth factor-beta 2 (TGF- $\beta 2$ ), a protein that is massively produced by high-grade gliomas and promotes tumour cell proliferation, angiogenesis, invasion and metastasis. Thus, inhibiting TGF- $\beta 2$ production exerts multiple antitumor effects (56).

RNA interference (RNAi) is a post-transcriptional process triggered by the introduction of double-stranded RNA (dsRNA) which leads to gene silencing in a sequence-specific manner. With this technology, the targeted genes essential for survival or progression of cells can be knocked down. A likely candidate for the RNAi therapy of gliomas is the in- hibitor of apoptosis protein, survivin. Survivin is involved in cell division and inhibition of apoptosis (57). It is anticipated that an increase in survivin steady-state levels enhances the resistance of cancer cells to chemotherapeutic drugs or radiation (58).

\section{Role of nanobiotechnology in gene therapy of brain tumours}

Gene therapy is a new concept in the treatment of glioblastoma multiforme, which is based on the ability to replace a defective gene through the delivery and integration of a fully functional version of the same gene. Originally, this 
method was reserved for genetic diseases but recently, its attention is being focused on cancer therapy. Tumours develop through multiple, known and unknown, genetic abnormalities. Moreover, every tumour has a different accumulation of mutations that need to be addressed specifically. Several methods for gene therapy have been tested successfully in preclinical stages. Some of the major approaches employed for gene therapy of GBM include:

A. Delivery of tumour-suppressor genes to reprogram tumour cells into apoptosis (reprogramming).

B. Delivery of conditionally-replicating viruses to specifically lyse tumour cells while sparing normal tissue (oncolysis).

C. Delivery of suicide genes to convert pro-drugs in the tumour and achieve tumour cell death (suicide genes).

D. Delivery of cytokine genes to activate and attract immune cells against tumour (immune activation).

The delivery of foreign genetic material has usually been done using recombinant viruses, but alternative vehicles such as stem cells, nanoparticles and liposomes, has also been extensively developed and reached the clinical stage (59).

\subsection{Virus-based Gene Therapy of GBM}

The first attempt to treat gliomas with a non-engineered virus was an unsuccessful study conducted in 1982 using attenuated mumps virus (60). In the following decades, retroviruses and Herpes simplex virus (HSV) were used. As mentioned above, there can be different strategies in the delivery of a suicide gene such as HSV-derived enzyme Thymidine Kinase (61). This enzyme catalyses the phosphorylation of cytotoxic nucleoside analogues that can be incorporated into the DNA of actively proliferating cells, disrupting DNA replication and halting cell division. Oth- er widely studied suicide genes are the bacterial enzyme Cytosine Deaminase, which converts the pro-drug 5-fluorcytosine into the toxic compound 5-fluoruracil; or E. coli derived Purine Nucleoside Phosphorylase (PNP), which converts non-toxic adenosine ribonucleosides into toxic adenine analogues that disrupt RNA processing.

The viral delivery of tumour-suppressor genes is also very promising because there are different mutations of these genes in most gliomas. The delivery of this type of genes is supposed to restore normal or higher apoptosis in tumour cells, among the eligible genes are $\mathrm{p} 53, \mathrm{p}^{16 \mathrm{NK} 4 \mathrm{a}}$, Phosphatase and Tensin Homologue (PTEN), and p27. Despite many particularly successful studies, there are still serious limitations which include poor gene transfer, lack of bystander effect, and potential resistance arising from the inherent genetic heterogeneity within GBM cells.

Immunomodulation is based on the delivery of genes such as IFN-gamma-inducible protein 10, TNF-alpha, and several interleukins. The difficulty in this approach lies in that the CNS is relatively isolated from systemic immune responses and it is therefore difficult to induce the immune system to mount an effective local anti-tumour response against gliomas (62). This difficulty is increased by the ability of glioma cells to suppress and effectively evade cellular immune responses $(59,62)$.

\subsection{Stem Cell-Based Gene Therapy of GBM}

Another type of delivery vehicle able to deliver therapeutic genes into tumour cells are stem cells. While stem cells have been studied for only half as long as viral carriers and only recently reached the clinical stage, they have been proved as one of the most attractive vehicles for the combination of gene therapy with viral therapy and other conventional therapy strategies. Their major advantage

Tab. 2: Running clinical trials.

\begin{tabular}{|l|l|c|c|}
\hline Identifier & Aim of the study & Phase & Particle \\
\hline NCT01301430 & $\begin{array}{l}\text { Phase I/IIa Study of Intratumoral/Intracerebral or Intravenous/Intracerebral } \\
\text { Administration of Parvovirus H-1 (ParvOryx) in Patients With Progressive Primary } \\
\text { or Recurrent Glioblastoma Multiforme. }\end{array}$ & II & virus \\
\hline NCT01906385 & $\begin{array}{l}\text { Initial Study to Determine the Maximum Tolerated Dose, Safety and Efficacy } \\
\text { of Rhenium Nanoliposome in Recurrent Glioblastoma. }\end{array}$ & II & nanoliposome \\
\hline NCT01156584 & $\begin{array}{l}\text { Ascending Dose Trial of the Safety and Tolerability of Toca 511 in Patients With } \\
\text { Recurrent High Grade Glioma. }\end{array}$ & II & virus \\
\hline NCT00734682 & $\begin{array}{l}\text { A Phase I Trial of Nanoliposomal CPT-11 (NL CPT-11) in Patients With Recurrent } \\
\text { High-Grade Gliomas. }\end{array}$ & nanoliposome \\
\hline NCT01956734 & $\begin{array}{l}\text { Phase I Trial of Combination of DNX-2401 (Formerly Named Delta-24-RGD) } \\
\text { Oncolytic Adenovirus With a Short Course of Temozolomide for Treatment of Glio- } \\
\text { blastoma at First Recurrent. }\end{array}$ & virus \\
\hline NCT00390299 & $\begin{array}{l}\text { Phase I Trial of a Measles Virus Derivative Producing CEA (MV-CEA) in Patients } \\
\text { With Recurrent Glioblastoma Multiforme (GBM). }\end{array}$ & I & virus \\
\hline NCT02062827 & $\begin{array}{l}\text { A Phase I Study of M032 (NSC 733972), a Genetically Engineered HSV-1 Express- } \\
\text { ing IL-12, in Patients With Recurrent/Progressive Glioblastoma Multiforme. }\end{array}$ & I & virus \\
\hline
\end{tabular}


against other vehicles is their ability to migrate toward tumour cells even when injected peripherally (63). This is extremely useful in the treatment of disseminating tumours, in which GBM is included. In general, there are three types of stem cells: neural, mesenchymal and embryonic. Mesenchymal stem cells can be genetically engineered to express therapeutic cytokines such as interleukin 2 or interferon $\gamma$ $(64,65,66)$.

\subsection{Nanotechnology-Based Gene Therapy of $G B M$}

As a fully synthetic technology, nanoparticles, liposomes, and polymers, have become of great interest for gene delivery into malignant gliomas. There are several types of nanoparticles currently undergoing clinical trials and the tested genetic treatments are similar to those carried by viruses and stem cells (59).

\section{Conclusion}

These relatively new technologies derive their benefits from the unique properties of nanoparticles and their complexes with cytostatics, virostatics, antibiotics and other agents. They enables the delivery of therapeutic drugs across the blood-brain barrier and, at the same time, diminishes the dangerous side effects of the treatment, thus eliminating the manifestation of acute and chronic toxicity. The use of nanotechnology enables a more efficient targeted therapy against cancer cells than casual non-specific chemotherapy. Such effect could be amplified by the use of liposomal nanoparticles as carriers along with other active molecules directed to specific molecular pathways regulating cell proliferation and survival. The enhancement of these treatments is important in dealing with "residual disease", metastasis, and delay the development of therapy resistance mechanisms of cancer cells. Experimental, as well as clinical trials have already proved that molecular interactions can be specifically targeted ensuring their expression only in cancer cells, sparing healthy cells from the negative effects of the treatment.

\section{Grants support}

Supported by the European Union Social Fund project on "Human Resources for Neurosciences in the Hradec Kralove and Usti Regions", Ministry of Education, Youth and Sports of the Czech Republic (grant ID \# CZ.1.07/2.3.00/20.0274) and PRVOUK 36/07. Dr. Diaz-Garcia was supported by the Czech Republic State Budget's project no. CZ.1.07/2.3.00/30.0022.

\section{Conflicts of interest}

The authors declare that there are no conflicts of interest regarding the preparation or content of this article.

\section{References}

1. Invernici G, Cristini S, Alessandri G, et al. Nanotechnology advances in brain tumors: The state of the art. Recent Patents on Anti-Cancer Drug Discovery 2011; 6: 58-69.

2. Lockman PR, Mumper RJ, Khan MA, Allen DD. Nanoparticle technology for drug delivery across the blood-brain barrier. Drug Dev Ind Pharm 2002; 28: 1-13.

3. Béduneau A, Saulnier P, Benoit JP. Active targeting of brain tumors using nanocarriers. Biomaterials 2007; 28: 4947-67.

4. Ferrari M. Cancer nanotechnology: Opportunities and challenges. Nat Rev Cancer 2005; 5: 161-71.

5. Gabathuler R. Approaches to transport therapeutic drugs across the blood-brain barrier to treat brain diseases. Neurobiol Dis 2010; 37(1): 48-57.

6. Grabrucker AM, Chhabra R, Belletti D, et al. Nanoparticles as Blood-Brain Barrier Permeable CNS Targeted Drug Delivery Systems. Top Med Chem 2014; 10: 71-89.

7. Matsumura Y, Maeda H. A new concept for macromolecular therapeutics in cancer chemotherapy: mechanism of tumoritropic accumulation of proteins and the antitumor agent SMANCS. Cancer Res 1986; 46: 6387-6392.

8. Zhang L, Liu Y, Yu D, Zhangl N. Gadolinium-loaded chitosan nanoparticles as magnetic resonance imaging contrast agents for the diagnosis of tumor. J Biomed Nanotechnol 2013 May; 9(5): 863-9.

9. Reardon DA, Wen PY, Mellinghoff IK. Targeted molecular therapies against epidermal growth factor receptor: Past experiences and challenges. Neuro Oncol 2014 Oct; 16(suppl 8): viii7-viii13.

10. Kateb B, Chiu K, Black KL, et al. Nanoplatforms For Constructing New Approaches To Cancer Treatment, Imaging, And Drug Delivery: What Should Be The Policy? Neuroimage 2011; Jan; 54(Suppl 1): S106-24.

11. Sahay G, Kim JO, Kabanov AV, et al. The exploitation of differential endocytic pathways in normal and tumor cells in the selective targeting of nanoparticulate chemotherapeutic agents. J Biomaterials 2010; 31(5): 923-933.

12. Miki K, Oride K, Inoue S, et al. Ring-opening metathesi polymerization-based synthesis of polymeric nanoparticles for enhanced tumor imaging in vivo: synergistic effect of folate-receptor targeting and pegylation. J Biomaterials 2010; 31(5): 934-42.

13. Kreuter J, Ramge P, Petrov V, et al. Direkt evidence that polysorbate-80-coated poly(butylcyanoacrylate) NPs deliver druha of the CNS via specific mechanisms requiring prior binding of drug to the NPs. Pharm Res 2003; 20: 409-16.

14. Panyam J, Zhou WZ, Prabha S, Sahoo SK, Labhasetwar V. Rapid endo-lysosomal escape of poly(DL-lactide-co-glycolide) NPs: Implications for drug and gene delivery. FASEB J 2002; 16: 1217-26.

15. Chen Y, Davwadi G, Benson HAE. Drug delivery across the blood-brain barrier. Cur Drug Deliv 2004; 1: 361-376.

16. Le Ray AM, Vert M, Gautier JC, Benoit JP. Fate of [14C]poly(-lactide-co-glycolide) nanoparticles after intravenous and oral administration to mice. Int J Pharm 1994; 106: 201-11.

17. Verrecchia T, Spenlehauer G, Bazile DV, et al. Non-Stealth (poly(lactic acid/albumin)) and stealth (poly(lactic acid-polyethylene glycol)) nanoparticles as injectable drug carriers J Control Rel 1995; 36: 49-61.

18. Ramos-Cabrer P, Campos F. Liposomes and nanothechnology in drug development focus on neurological targets. Int J Nanomedicine 2013; 8: 951-960.

19. Gosk S, Vermehren C, Storm G, Moos T. Targeting Anti-Transferrin Receptor Antibody (OX26) and OX26-Conjugated Liposomes to Brain Capillary Endothelial Cells Using In Situ Perfusion. Journal of Cerebral Blood Flow \& Metabolism 2004; 24: 1193-1204.

20. Wen CJ, Zhang LW, Al-Suwayeh SA, Yen TC, Fang JY. Theranostic liposomes loaded with quantum dots and apomorpine for brain targeting and bioimaging. Int J Nanomedicine 2012; 7: 1599-1611.

21. Walter KA, Tamargo RJ, Olivi A, Burger PC, Brem H. Intratumoral chemotherapy. Neurosurgery $1995 ; 37: 1128-1145$.

22. Cummings J, McArdle CS. Studies on the in vivo disposition of adriamycin in human tumours which exhibit different responses to the drug. Br J Cancer 1986; 53: $835-838$.

23. Allen TM, Cullis PR. Drug delivery systems: Entering the mainstream. Science 2004; 303: 1818-1822.

24. Madhankumar AB, Slagle-Webb B, Wang X, et al. Efficacy of interleukin-13 receptor-targeted liposomal doxorubicin in the intracranial brain tumor model. Mol Cancer Ther 2009; 8: 648-654.

25. Hong HY, Lee HY, Kwak W, et al. Phage display selection of peptides that home to atherosclerotic plaques: $\mathrm{Il}-4$ receptor as a candidate target in atherosclerosis. J Cell Mol Med 2008; 12: 2003-2014.

26. Gonzalo T, Muňoz-Fernández A. Dendrimeros y susaplicaciones biomédicas, monografia XXVIII: Nanotecnológia farmaceutica. Madrid: Real Academia Nacional de Farmácia, 2009.

27. Bravo-Osuna I, Herrero-Vanrell, R. Potencial de dendrímeros como vehiculo de fármacos em oftalmologia. Archovos de La Sociedad Espaňola de Oftalmologia 2007; 82(2): 60-70.

28. Wolinski JB, Grinstaff MW. Therapeutic and diagnostic applications of dendrimers for cancer treatment. Advanced Drug Delivery Reviews 2008; 60(9): 1037-1055. 
29. Mishra I. Dendrimer: a novel drug delivery system. Journal of Drug Delivery and Therapeutics 2011; 1(2): 70-74.

30. Triesscheijn M, Baas P, Schellens JH, Stewart FA. Photodynamic therapy in onkology. Oncologist 2006; 11: 1034-1044.

31. Wiener EC, Brechbiel MW, Brothers H, et al. Dendrimer/based metal chelates:a new class of magnetic resonance imaging contrast agents. Magn Reson Med 1994; 31: $1-8$.

32. Baek SK, Makkouk AR, Krasieva T, Sun CH, Madsen SJ, Hirschberg H. Photothermal treatment of glioma: an in vitro study of macrophage-mediated delivery of gold nanoshells. J Neurooncol 2011; 104(2): 439-448.

33. You J, Zhang G, Li C. Exceptionally high payload of doxorubicin in hollow gold nanospheres for near-infrared light-triggered drug release. ACS Nano 2010; 4 1033-41.

34. Lodhia J, Mandarano G, Ferris N, et al. Development and use of iron oxide nanopartiles (part 1): Synthesis of iron oxide nanoparticles for MRi. Biomed Imaging Interv J 2010: 6e12.

35. Corot C, Robert P, Idee JM, et al. Recent advances in iron oxide nanocrystal technology for medical imaging. Adv Drug Deliv Rev 2006; 58: 1471-504

36. Pan D, Caruthers SD, Hu G, et al. Ligand-directed nanobialys as theranostic agent for drug delivery and manganese-based magnetic resonance imaging of vascular targets. J Am Chem Soc 2008; 130: 9186-7.

37. Na HB, Lee JH, An K, et al. Development of a T1 contrast agent for magnetic resonance imaging using $\mathrm{MnO}$ nanoparticles. Angew Chem Int Ed Engl 2007; 46 $5397-401$.

38. Bridot JL, Faure AC, Laurent S, et al. Hybrid gadolinium oxide nanopaticles: multimodal contrast agents for in vivo imaging. J Am Chem Soc 2007; 129: 5076-84

39. Bourrinet $\mathrm{P}$, Bengele $\mathrm{HH}$, Bonnemain $\mathrm{B}$, et al. Preclinical safety and pharmacokinetic profile of ferumoxtran-10, an ultrasmall superparamagnetic iron oxide magnetic resonance contrast agent. Invest Radiol 2006; 41: 313-24.

40. Neuwelt EA, Varallyay CG, Manninger S, et al. The potential of ferumoxyto nanoparticle magnetic resonance imaging, perfusion, and angiography in central nervous system malignancy: a pilot study. Neurosurgery 2007 ; 60; 601-44. Discussion 611-2.

41. Neuwelt EA, Hamilton BE, Varallyay CG, et al. Ultrasmall superparamagnetic iron oxides (USPIOs): a future alternative magnetic resonance (MR) contrast agents for patients at risk fro nephrogenic systemic fibrosis (NSF)? Kidney Int 2009; 75 : 465-74.

42. Hadjipanayis CG, Machaidze R, Kaluzova M, et al. EGFRvIII antibody-conjugated iron oxide nanoparticles for magnetic resonance imaging-guided convection-enhanced delivery a targeted therapy of glioblastoma. Cancer Res 2010; 70; 6303-12.

43. Soroceanu L, Gillespie Y, Khazaeli MB, et al. Use of chlorotoxin for targeting of primary brain tumors. Cancer Res 1998; 58: 4871-9.

44. Lyons SA, O'Neal J, Sontheimer H. Chlorotoxin, a scorpion-derived peptide, specifically binds to gliomas and tumors of neuroectodermal origin. Glia 2002; 39; 162-73.

45. Lee JH, Jang JT, Choi JS, et al. Exchange-coupled magnetic nanoparticles for efficient heat induction. Nature Nanotechnology $2011 ; 6: 418-22$.

46. Sharma R, Chen CJ. Newer nanoparticles in hyperthermia treatment and thermotherapy. Journal of Nanoparticle Research 2009; 11: 671-689.

47. Maier-Hauff K, Ulrich F, Nestler D, et al. Efficacy and safety of intratumoral thermotherapy using magnetic iron-oxide nanoparticles combined with external beam radiotherapy on patients with recurrent glioblastoma multiforme. J Neurooncol 2011 Jun; 103(2): 317-24.

48. Sahoo NG, Bao H, Pan Y, et al. Functionalized carbon nanomaterials as nanocarriers for loading and delivery of a poorly water-soluble anticancer drug: A comparative study. Chem Commun (camb) 2011; 47: 5235-5237.

49. Utreja P, Jain S, Tiwary AK. Novel drug delivery systems for sustained and targeted delivery of anti-cancer drugs: Current status and future prospects. Curr Drug Deliv 2010; 7: 152-161

50. Bianco A, Kostarelos K, Prato M. Applications of carbon nanotubes in drug deliverz. Curr Opin Chem Biol 2005; 9: 674-679.

51. Kam NW, O'Connell M, Wisdom JA, Dai H, Carbon nanotubes as multifunctional biological transporters and near-infrared agents for selective cancer cell destruction. Proc Natl Acad Sci USA 2005; 102: 11600-11605.

52. Liu Z, Sun X, Nakayama-Ratchford N, Dai H. Supramolecular chemistry on water-soluble carbon nanotubes for drug loading and delivery ACS Nano 2007; 1 : $50-56$.
53. Ong LC, Chung FF, Tan YF, Leong CO. Toxicity of single-walled carbon nanotubes. Arch Toxicol 2014 Oct 2 (Epub ahead of print).

54. Bhirde AA, Patel S, Sousa AA, et al. Distribution and clearance of PEG-singlewalled carbon nanotube cancer drug delivery vehicles in mice. Nanomedicine (Lond) 2010 Dec; 5(10): 1535-46.

55. Caruso G, Caffo M, Raudino G, Alafaci C, Salpietro FM, Tomasello F. Antisense Oligonucleotides as an Innovative Therapeutic Strategy in the Treatment of HighGrade Gliomas. Recent Pat CNS Drug Discov 2010; 5(1): 56-69.

56. Catuogno S, Esposito CL, Quintavalle C, Condorelli G, Franciscis V de, Cerchia L. Nucleic Acids in Human Glioma Treatment: Innovative Approaches and Recent results. J Signal Transduct 2012; 2012: 735135 .

57. Hendruschk S, Wiedemuth R, Aigner A, et al. RNA interference targeting survivin exerts antitumoral effects in vitro and in established glioma xenografts in vivo. Neuro-oncology 2011; 13(10): 1074-1089.

58. Pennati M, Folini M, Zaffaroni N. Targeting survivin in cancer therapy. Expert Opin Ther Targets 2008; 12(4):4 63-476.

59. Kwiatkowsk A, Nandhu MS, Behera P, Chiocca EA, Viapiano MS. Strategies in Gene Therapy for Glioblastoma Cancers 2013; 5: 1271-1305.

60. Yumitori K, Handa H, Yamashita J, Suda K, Otsuka S, Shimiyu Y. Treatment of malignat glioma with mumps virus. No Shinkei Geka 1982; 10: 143-147.

61. Assi H, Candolfi M, Baker G, Mineharu Y, Lowenstein PR, Castro MG. Gene therapy for brain tumors: Basic developments and clinical implementation. Neurosci Lett 2012; 527: 71-77.

62. Natsume A, Yoshida J. Gene therapy for high-grade glioma: Current approaches and future directions. Cell Adhes Migr 2008; 2: 186-191.

63. Aboody KS, Brown A, Rainov NG, et al. Neural stem cells display extensive tropism for pathology in adult brain: Evidence from intracranial gliomas. Proc Natl Acad Sci USA 2000; 97: 12846-12851.

64. Stagg J, Lejeune I, Paquin A, Galipeau J. Marrow stromal cells for interleukin-2 delivery in cancer immunotherapy. Hum Gene Ther 2004; 75: 597-608.

65. Gunnarsson S, Bexell D, Svensson A, et al. Intratumoral IL-7 delivery by mesenchyml stromal cells potentiates IFN-gamma-transduced tumor cell immunotherapy of experimental glioma. J Neuroimmunol 2010; 218: 140-144.

66. Altaner C, Altanerova V. Stem cell based glioblastoma gene therapy. Neoplasma 2012; 59(6): 756-760

67. Faucher L, Guay-Bégin AA, Lagueux J, Côté MF, Petitclerc E, Fortin MA. U1tra-small gadolinium oxide nanoparticles to image brain cancer cells in vivo with MRI. Contrast Media Mol Imaging 2011 Jul-Aug; 6(4): 209-18.

68. Xin H, Jiang X, Gu J, et al. Angiopep-conjugated poly(ethylene glycol)-copoly( $\varepsilon$-caprolactone) nanoparticles as dual-targeting drug delivery system for brain glioma. Biomaterials 2011; 32(18): 4293-4305.

69. Ananda S, Nowak AK, Cher L, Dowling A, Brown C, Simes J, Rosenthal MA Cooperative Trials Group for Neuro-Oncology (COGNO). Phase 2 trial of temozolomide and pegylated liposomal doxorubicin in the treatment of patients with glioblastoma multiforme following concurrent radiotherapy and chemotherapy. J Clin Neurosci 2011 Nov; 18(11): 1444-8.

70. Dhanikula RS, Argaw A, Bouchard JF, Hildgen P. Methotrexate loaded polyether-copolyester dendrimers for the treatment of gliomas: enhanced efficacy and intratumoral transport capability. Mol Pharm 2008 Jan-Feb; 5(1): 105-16.

71. Day ES, Thompson PA, Zhang L, et al. Nanoshell-mediated photothermal therapy improves survival in a murine glioma model. J Neurooncol 2011 Aug; 104(1): 55-63.

72. Tobias AL, Thaci B, Auffinger B, et al. The Timing of Neural Stem Cell-Based Biotherapy is Critical for Optimal Therapeutic Efficacy when Applied with Radiation and Chemotherapy for the Treatment of Glioblastoma. Stem Cells Transl Med 2013 Sep; 2(9): 655-666.

73. Ning J, Wakimoto H. Oncolytic herpes simplex virus-based strategies: toward a breakthrough in glioblastoma therapy. Front Microbiol 2014; 5: 303.

74. Maier-Hauff K, Ulrich F, Nestler D, et al. Efficacy and safety of intratumoral thermotherapy using magnetic iron-oxide nanoparticles combined with external beam radiotherapy on patients with recurrent glioblastoma multiforme. J Neurooncol 2011 Jun; 103(2): 317-324.

75. Santos T, Fang X, Chen MT, et al. Sequential administration of carbon nanotubes and near-infrared radiation for the treatment of gliomas. Front Oncol $2014 \mathrm{Jul} ; 4$ : 180.

76. Jensen SA, Day ES, Ko CH, et al. Spherical Nucleic Acid Nanoparticle Conjugates as an RNAi-Based Therapy for Glioblastoma. Sci Transl Med 2013 Oct; 5(209): 209ra152.

Received: $18 / 05 / 2014$

Accepted in revised form: 21/01/2015

\section{Corresponding author:}

Petr Krůpa, MD, Department of Neurosurgery, Charles University Prague, Medical Faculty and University Hospital Hradec Králové, Czech Republic; e-mail: petrkrupa@centrum.cz 